\title{
PERSISTENT MULLERIAN DUCT SYNDROMNE WITH TRANSVERSE TESTICULAR ECTOPIA: A RARE CASE REPORT
}

T. Raghupathy ${ }^{1}$, J. Joyce Prabhakar², P. Sathish Prabhu ${ }^{3}$

\section{HOW TO CITE THIS ARTICLE:}

T. Raghupathy, J. Joyce Prabhakar, P. Sathish Prabhu. "Persistent Mullerian Duct Syndromne with Transverse Testicular Ectopia: A Rare Case Report". Journal of Evolution of Medical and Dental Sciences 2015;

Vol. 4, Issue 75, September17; Page: 13140-13143, DOI: 10.14260/jemds/2015/1891

ABSTRACT: We report a case of Persistent Mullerian Duct Syndrome (PMDS) with Transverse Testicular Ectopia (TTE) in a 27 yrs old male discovered during surgery for right irreducible inguinal hernia. Tension free hernioplasty and excision of pmds was done. The specimen sent for histopathologic examination (hpe). Hpe revealed pmds.

KEYWORDS: Irreducible hernia-two cord like structure separated by uterus like structure with both cornua leading to gonads-rudimentary uterus.

CASE REPORT: A 27 yrs. old unmarried male came with right groin swelling for 6 months which was reducible earlier, turned irreducible for past 8 hours. Patient had pain in right lower abdomen and vomiting. Vitals found to be normal. On examination tenderness present over right groin swelling, absent cough impulse, swelling irreducible, absent testis on left side, testis was palpable on right side. External gentila and secondary sexual characters seem to be normal. Patient was not aware of the absence of the left testis. Patient was diagnosed as a right irreducible inguinal hernia with left undescended testis. All basic investigations taken and was found to be normal. Planned for emergency inguinal exploration and hernia repair.

INTRAOPERATIVE: Under spinal anaesthesia, rt parainguinal incision made, inguinal canal opened and following findings noted:

1. Indirect sac.

2. Sac contents- two cord like structure separated by uterus like structure with both cornua leading to gonads;

- The uterus like structure was removed and both cord like structure along with gonads preserved and sent for hpe.

- Hernioplasty done for right irreducible inguinal hernia.

- Two cord like structure along with gonads placed in right hemiscrotum.

HPE REPORT: Macroscopic Appearance: Section shows slit like endometrial cavity measuring $5.5 * 4.2 \mathrm{cms}$.

Microscopic Appearance: Section shows bundles of smooth muscle fibres enclosing endometrial glands with stroma.

No evidence of any gonads in section studied hpe report: confirmative of rudimentary uterus. 


\section{CASE REPORT}

DISCUSSION: Male pseudohermaphroditism (pmds) characterized by presence of uterus, cervix, fallopian tubes in normal 46xy male.1,2

Tte- migration of testis to opposite side where both testis pass through same inguinal canal. Initially both male and female embryos have wolffian ducts and mullerian ducts.

Around 6-9 weeks of gestation, mullerian duct regresses due to mullerian inhibiting substance produced by sertoli cells in male. .,4 $^{2}$

Failure of regression leads to pmds. ${ }^{1}$

Pmds-autosomal recessive disorder with uterus, cervix and fallopian tubes in 46xy male. ${ }^{2}$ Cryptorchidism-testicular descent affected due to entanglement, testis may be present in ectopic sites.

Very rarely associate with tte.5,6

\section{PMDS Presentations: 6}

1. Discovered during hernia repair.

2. Abdominal surgery.

3. Incidental findings in usg /mri.

4. Infertility.

\section{Anatomical Variants: ${ }^{7}$}

1. One testis in sctrotum, uterus with derviatives in ingunial canal or brought made into it by gentle traction in presenting testis (most common type).

2. Contralateral testis (tte) in sac.

3. B/l cryptorchidism with testis embedded in broad ligaments in ovary position in respect to uterus.

Etiopathogenesis, differential diagnosis, operative strategy in pmds -not defined completely.

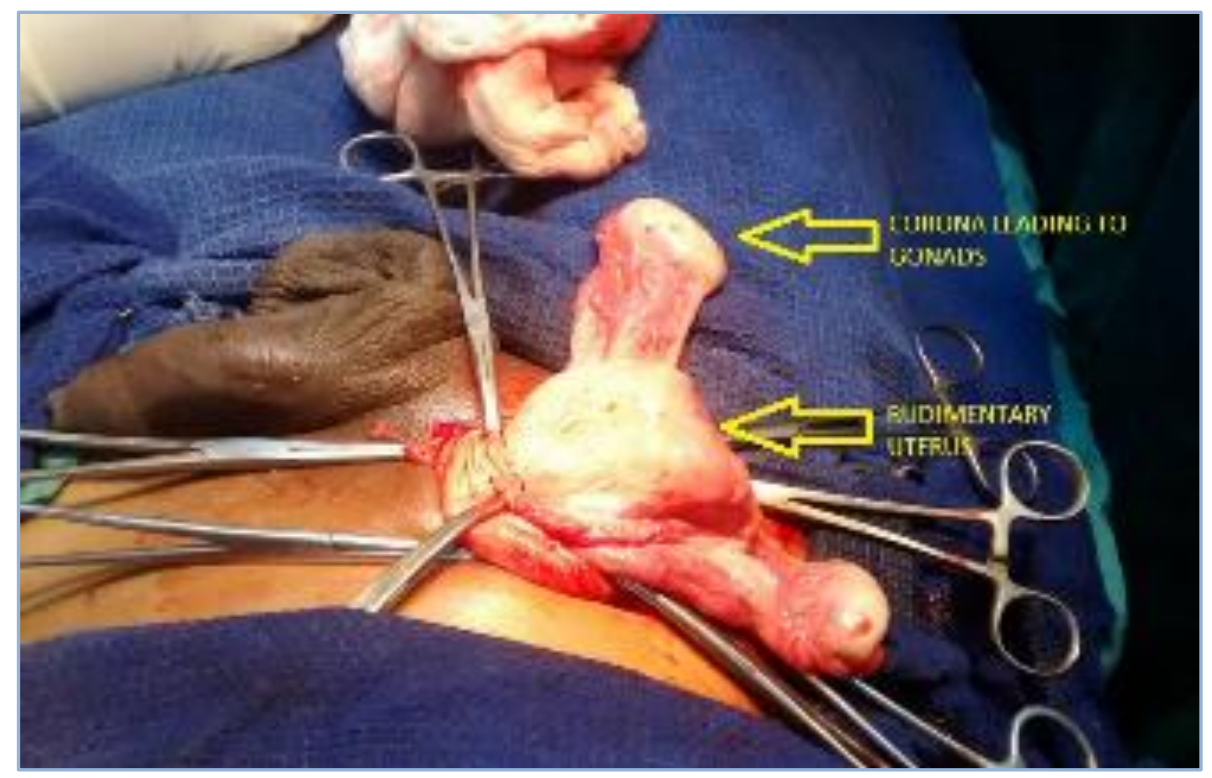

\section{Figure 1}




\section{CASE REPORT}

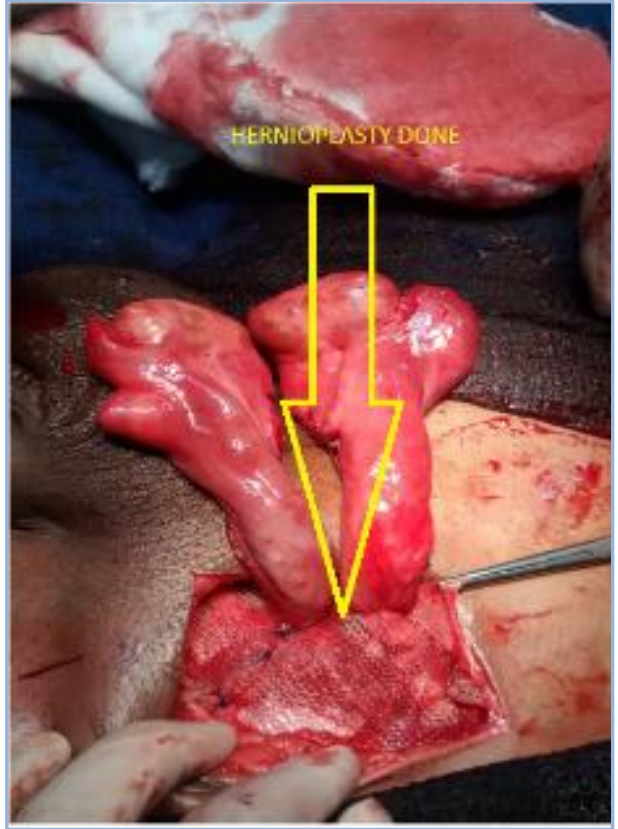

Figure 2

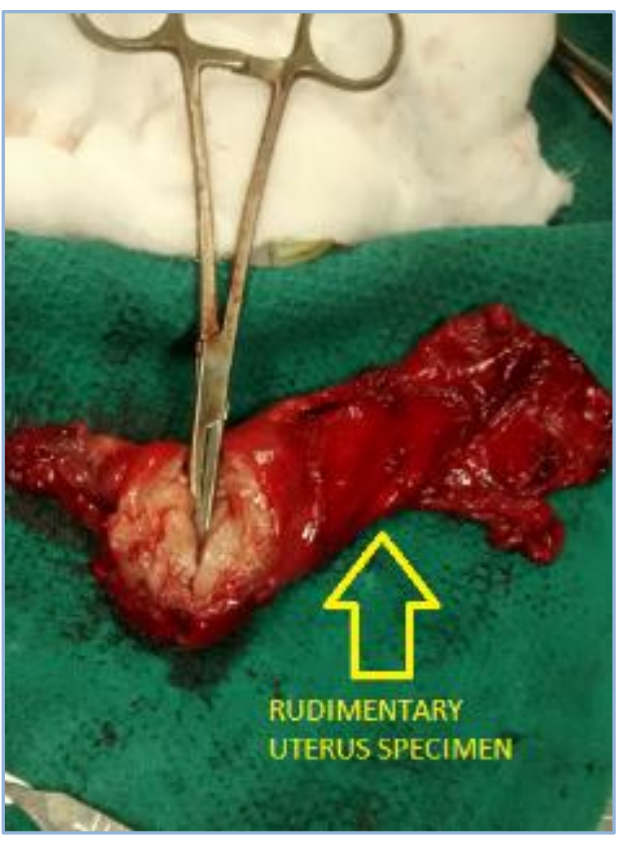

Figure 3

\section{REFERENCES:}

1. Imbeaud S, Belville C, Messika-Zeitoun L, Rey R, di Clemente N, Josso N, Picard JY. A 27 base-pair deletion of the anti-müllerian type II receptor gene is the most common cause of the persistent müllerian duct syndrome. Hum Mol Genet. 1996 Sep; 5(9): 1269-77. PubMed citation.

2. Josso N, Belville C, di Clemente N, Picard JY. AMH and AMH receptor defects in persistent Müllerian duct syndrome. Hum Reprod Update. 2005 Jul-Aug; 11(4): 351-6. Epub 2005 May 5. Review.PubMed citation.

3. Belville C, Van Vlijmen H, Ehrenfels C, Pepinsky B, Rezaie AR, Picard JY, Josso N, di Clemente N, Cate RL. Mutations of the anti-mullerian hormone gene in patients with persistent mullerian duct syndrome: biosynthesis, secretion, and processing of the abnormal proteins and analysis using a three-dimensional model. Mol Endocrinol. 2004 Mar; 18(3): 708-21. Epub 2003 Dec 12. PubMed citation.

4. Faure E, Gouédard L, Imbeaud S, Cate R, Picard JY, Josso N, di Clemente N. Mutant isoforms of the anti-Müllerian hormone type II receptor are not expressed at the cell membrane. J Biol Chem. 1996 Nov 29; 271(48): 30571-5. PubMed citation.

5. Josso N, Picard JY, Imbeaud S, di Clemente N, Rey R. Clinical aspects and molecular genetics of the persistent müllerian duct syndrome. Clin Endocrinol (Oxf). 1997 Aug; 47(2): 137-44. Review. PubMed citation.

6. Rey R. Anti-Müllerian hormone in disorders of sex determination and differentiation. Arq Bras Endocrinol Metabol. 2005 Feb; 49(1): 26-36. Epub 2006 Mar 16. Review. PubMed citation.

7. OMIM: PERSISTENT MULLERIAN DUCT SYNDROME, TYPES I AND II. 


\section{AUTHORS:}

1. T. Raghupathy

2. J. Joyce Prabhakar

3. P. Sathish Prabhu

\section{PARTICULARS OF CONTRIBUTORS:}

1. Professor, Department of General Surgery, Chengalpattu Medical College and Hospital.

2. Assistant Professor Department of General Surgery, Chengalpattu Medical College and Hospital.

FINANCIAL OR OTHER COMPETING INTERESTS: None
3. Junior Resident, Department of General Surgery, Chengalpattu Medical College and Hospital.

\section{NAME ADDRESS EMAIL ID OF THE} CORRESPONDING AUTHOR:

Dr. T. Raghupathy,

Professor,

Department of General Surgery,

Chengalpattu Medical College and Hospital.

E-mail: dr.traghupathy@gmail.com

Date of Submission: 26/08/2015.

Date of Peer Review: 27/08/2015.

Date of Acceptance: 11/09/2015.

Date of Publishing: 15/09/2015. 